\title{
Pressureless Sintered Nitride Composites in the $\mathrm{AlN}-\mathrm{Al}_{2} \mathrm{O}_{3}$ System
}

\author{
Young Woo Kim*, Kyu Heon Kim**, Dong Hyun Kim**, Seog Young Yoon,** and Hong Chae Park**`ं \\ *SOFC Research Project, Research Institute of Industrial Science and Technology, Pohang 790-330, Korea \\ **School of Materials Science and Engineering, Pusan National University, Pusan 609-735, Korea \\ (Received July 11, 2014; Revised September 1, 2014; Accepted September 2, 2014)
}

\section{$\mathrm{AlN}-\mathrm{Al}_{2} \mathrm{O}_{3}$ 계에서의 상압소결 질화물복합체 \\ 김영우* · 김규헌** . 김동현** · 윤석영** · 박홍채**,† \\ *포항산업과학연구원 $\mathrm{SOFC}$ 연구단 \\ ***부산대학교 재료공학부 \\ (2014년 7월 11일 접수 ; 2014년 9월 1일 수정 ; 2014년 9월 2일 채택)}

\begin{abstract}
Particulate nitride composites have been fabricated by sintering the compacted powder of $\mathrm{AlN}$ and $5-64.3 \mathrm{~mol} \% \mathrm{Al}_{2} \mathrm{O}_{3}, \mathrm{with}$ a small addition of $\mathrm{Y}_{2} \mathrm{O}_{3}\left(\mathrm{Y}_{2} \mathrm{O}_{3} / \mathrm{AlN}, 1 \mathrm{wt} \%\right)$, in 1-atm nitrogen gas at $1650-1900^{\circ} \mathrm{C}$. The composites were characterized in terms of sintering behavior, phase relations, microstructure and thermal shock resistance. AIN, 27R AIN pseudopolytype, and alminium oxynitride $\left(\mathrm{AlON}, 5 \mathrm{AIN} \cdot 9 \mathrm{Al}_{2} \mathrm{O}_{3}\right.$ ) were found to existin the sintered material. Regardless of batch composition, the $\mathrm{AlN}-\mathrm{Al}_{2} \mathrm{O}_{3}$ powder compacts exhibited similar sintering behavior; however, the degree of shrinkage commonly increased with increasing $\mathrm{Al}_{2} \mathrm{O}_{3}$ content, consequently giving high sintered bulk density. By increasing the $\mathrm{Al}_{2} \mathrm{O}_{3}$ addition up to $\geq 50 \mathrm{~mol} \%$, the matrix phase in the sintered material was converted from $\mathrm{AlN}$ or $27 \mathrm{R}$ to $\mathrm{AlON}$. Above $1850^{\circ} \mathrm{C}$, a liquid phase was formed by the reaction of $\mathrm{Al}_{2} \mathrm{O}_{3}$ with $\mathrm{AlN}$, aided by $\mathrm{Y}_{2} \mathrm{O}_{3}$ and mainly existed at the grain boundaries of AlON. Thermal shock resistance was superior in the sintered composite consisting of AlON with dispersed AIN or AIN matrix phase.
\end{abstract}

Key words : AlN, AlON, Sintering behavior, Thermal shock resistance

\section{1. 서 론}

질화알루미늄 $(\mathrm{AlN})$ 과 알루미늄산질화물 $(\mathrm{AlON})$ 은 높 은 열전도도, 고온에서의 우수한 전기 및 기계적 성질, 용 융금속에 대한 화학적 안정성 등의 장점을 보유하므로 유 용한 구조용 세라믹재료다. 2성분계 $\mathrm{AlN}-\mathrm{Al}_{2} \mathrm{O}_{3}$ 에서 유사 한 다형의 산질화물에 대하여 보고 ${ }^{1-3)}$ 되어 있다. 그들 중 의 하나인 스피넬 구조의 $\mathrm{AlON}$ 이 Yamaguchi ${ }^{4)}$ 에 의해서 처음으로 확인되었으나 이의 안정화 영역범위에 대해서 는 논란이 있다. Willems등 ${ }^{5}$ 은 $\mathrm{AlON}$ 은 단지 제한된 범위 의 산소 및 질소분압 하에서만 안정하다는 것과 아울러 $\mathrm{AlON}$ 의 생성반응은 너무 느려 $1750^{\circ} \mathrm{C}$ 이하의 온도에서 는 평형에 도달할 수 없다는 것을 그 이유로 제시하였다. $\mathrm{AlON}$ 은 양론조성 $5 \mathrm{AlN} \cdot 9 \mathrm{Al}_{2} \mathrm{O}_{3}$ 를 가지며 $2050^{\circ} \mathrm{C}$ 부근에 서 alumina-rich한 안정한 액상과 nitride-rich한 불안정 (휘

${ }^{\dagger}$ Corresponding author : Hong Chae Park E-mail : hcpark1@pusan.ac.kr

Tel : +82-51-510-2392 Fax : +82-51-512-0528
발성)액상으로 비조화용융 (incongruently melting)한다. $\left.{ }^{6}\right)$

$\mathrm{AlON}$ 의 제조공정기술 ${ }^{7)}$ 로는 $\mathrm{Al}_{2} \mathrm{O}_{3}$ 의 환원-질화 (reductionnitridation), 연소반응에 의한 금속 $\mathrm{Al}$ 의 산질화 (oxynitridation), $\mathrm{AlCl}_{3}$ 를 함유하는 기상반응, $\mathrm{AlN}$ 과 $\mathrm{Al}_{2} \mathrm{O}_{3}$ 의 직접 반응법 등이 알려져 있다. 이 중에서 산화물과 질화물의 직접반응법이 가장 널리 이용되며, $\mathrm{AlN}$ 은 $\mathrm{Al}_{2} \mathrm{O}_{3}$ 와 반응 하여 $1650^{\circ} \mathrm{C}$ 이상에서 $\mathrm{AlON}$ 을 생성한다. ${ }^{6,8,9)} \mathrm{AlON}$ 의 소 결에 관한 연구는 비교적 적은 편이다. ${ }^{10-12)}$ 이를 요약하 면, 초기 반응소결단계에서는 증발-응축기구가 치밀화를 지배한다. 즉, 치밀화 없이 표면적을 감소시키는 이 기구 에 의한 물질의 이동을 최소화하기 위해서는 $\mathrm{AlN}$ 과 $\mathrm{Al}_{2} \mathrm{O}_{3}$ 의 휘발을 억제시킬 수 있도록 분위기를 조절해야 한다. 소결조제의 존재는 전이액상을 생성하여 초기 소결할 동 안 액상소결을 증진시킨다. $1300-1500^{\circ} \mathrm{C}$ 의 온도범위에서 물질내부를 통한 이온의 확산이 일어난다. 또한 $1600^{\circ} \mathrm{C}$ 이상에서는 체적확산에 의해서 치밀화가 진행된다.

2성분계 $\mathrm{AlN}-\mathrm{Al}_{2} \mathrm{O}_{3}$ 에 대하여 다양한 연구가 행하여지 고 있으나, 그 결과는 조성범위와 반응조건에 따라 상이 하다. 본 연구에서는 35.7-95 mol\% $\mathrm{AlN}$ 을 함유하는 알 
루미나 압분체를 질소분위기에서 $1650-1900^{\circ} \mathrm{C}$ 상압소결 시 일어나는 소결거동, 상관계, 미세구조를 관찰하였으며 격자정수를 측정하고 소결체의 열충격저항성을 검토하였 다. 이 반응계에서 조성범위에 따른 반응소결, 미세구조의 발달, 기계적 성질, 열확산에 관한 연구결과를 이미 보고 ${ }^{13-}$ 15)하였다.

\section{2. 실험 방법}

AlN (F-grade, Tokuyama Soda)과 $\mathrm{Al}_{2} \mathrm{O}_{3}$ (AES-11-C, Sumitomo Chemicals)를 출발물질로 사용하였다. $\mathrm{AlN}$ 분말의 중위경과 비표면적은 $0.6 \mu \mathrm{m}$ 과 $8.2 \mathrm{~m}^{2} / \mathrm{g}$ 이었으며 $\mathrm{Al}_{2} \mathrm{O}_{3}$ 분 말의 그것은 각각 $0.5 \mu \mathrm{m}$ 과 $4.1 \mathrm{~m}^{2} / \mathrm{g}$ 이었다. 알루미나에 $\mathrm{AlN}$ 을 $35.7-95 \mathrm{~mol} \%$, $\mathrm{AlN}$ 함량 기준으로 $1 \mathrm{wt} \% \mathrm{Y}_{2} \mathrm{O}_{3}$ 가 되도록 $\mathrm{Y}\left(\mathrm{NO}_{3}\right)_{3} \cdot 5 \mathrm{H}_{2} \mathrm{O}(99.9 \%$, Aldrich Chemicals)를 첨 가하였다. 배치분말을 폴리에칠렌 용기에 알루미나 볼과 함께 넣고 에탄올를 매체로 하여 48시간 ball milling하였다. 이 때 분산제로 $0.3 \mathrm{wt} \%$ DARVAN-C (R. T. Vanderbilt)와 $0.5 \mathrm{wt} \%$ PVB (Aldrich Chemicals) 결합재를 첨가하였다. 건조한 혼합분말을 50 mesh 이하로 미분쇄하고 $70 \mathrm{MPa}$ 의 압력으로 die pressing한 후, $200 \mathrm{MPa}$ 의 압력으로 냉간 정수압하였다.

유기물질을 제거시키기 위하여 공기 중 $500^{\circ} \mathrm{C}$ 에서 성 형체를 하소한 후, 분위기 가압 소결로 (GPS furnace, FPW 100/150-2200-100-LA, KCE Special Furnace)를 이용하여 $1200^{\circ} \mathrm{C}$ 까지는 진공, 그 이상의 온도에서는 1 기압의 질소 가스 분위기로 $1650-1900^{\circ} \mathrm{C}$ 범위의 소정의 온도에서 2 시간 소결하였다.

서로 다른 배치조합의 소성수축을 $5 \times 15 \mathrm{~mm}$ 크기의 성 형체를 이용하여 GPS로에 부착된 dilatometer를 이용하여 측정하였으며, 물을 매체로 하는 Archimedes 원리를 이용 하여 소결체의 부피밀도를 측정하였다. 결정상의 분석을 $\mathrm{XRD}$ (D-MAX 1400, Rigaku)를 이용하였다. AlON과 $\mathrm{AlN}$ 의 격자상수를 결정하기 위하여 $\mathrm{XRD}$ 에 내장된 lattice parameter program (rotating anode system 사용)으로 계산 하였으며, 이를 위하여 10 개의 $\mathrm{AlON}$ 회절피크와 9개의 $\mathrm{AIN}$ 피크를 선택하여 각각의 평균값을 이용하였다. SEM (JSM-840A, Jeol)을 이용하여 소결체의 미세구조를 관찰 하였다. 또한, 소결체의 표면을 diamond slurry를 사용하 여 연마하고, 이어서 질소분위기에서 $1400^{\circ} \mathrm{C}, 30$ 분간 thermal etching한 후, EPMA (JXA-8600, Jeol)를 이용하 여 line profile함으로써 질소와 산소의 농도분포를 조사하 였다. 소결된 시편의 입계와 이차상의 분석을 주사투과전 자현미경 (STEM, JEM-200CX, Jeol)을 이용하여 수행하 였다.

열충격저항 측정을 위한 시편의 제작 및 측정조건은 다 음과 같다. 각재형 소결체 $(30 \times 50 \mathrm{~mm})$ 의 양면을 diamond grit $325,600,1000$ 으로 차례로 연마한 후, multi-cutter MX-833, Maruto)를 이용하여 폭 $4 \mathrm{~mm}$, 두께 $3 \mathrm{~mm}$ 크기 의 시편으로 절단하였다. 각 시편을 공기 중에서 $7^{\circ} \mathrm{C} / \mathrm{min}$ 의 속도로 소정의 온도까지 가열시켜 1 시간 유지한 후, $25^{\circ} \mathrm{C}$ 증류수에 떨어뜨렸다. 먼저 $100^{\circ} \mathrm{C}$ 간격으로 $800^{\circ} \mathrm{C}$ 까지 열충격시험을 행하고, 강도의 저하가 현저한 구간에 서는 온도를 세분하여 실험하였다. 꺾임강도의 측정은 inner span $10 \mathrm{~mm}$, outer span $30 \mathrm{~mm}$, crosshead speed $0.5 \mathrm{~mm} / \mathrm{min}$ 의 조건으로 4점법으로 행하였다.

\section{3. 결과 및 고찰}

$\mathrm{AlN}-\mathrm{Al}_{2} \mathrm{O}_{3}$ 압분체의 소결거동에 미치는 $\mathrm{AlN}$ 첨가의 영 향을 조사하였다. $\mathrm{AlN}$ 의 첨가량에 관계없이 거의 유사한 패턴의 소성수축거동(Fig. 1)을 나타내었으나 온도에 따른 수축의 정도는 차이가 있었다. $35.7 \mathrm{~mol} \% \mathrm{AlN}$ 을 첨가한 경우는 $1700^{\circ} \mathrm{C}$ 에서 약 $14.5 \%$ 의 선수축을, $1450^{\circ} \mathrm{C}$ 부근에 서 최대의 수축속도를 나타내었다. 또한, $50 \mathrm{~mol} \% \mathrm{AlN}$ 을 첨가한 물질에서는 $1800^{\circ} \mathrm{C}$ 에서 약 $16 \%$ 의 수축률을, 1420 및 $1670^{\circ} \mathrm{C}$ 부근에서 두 번의 큰 수축속도를 나타낸 반면 에, $70 \mathrm{~mol} \%$ 첨가의 경우는(Fig. 1) 이 보다 $100^{\circ} \mathrm{C}$ 정도 높은 1520 및 $1770^{\circ} \mathrm{C}$ 부근에서 커다란 수축속도를 나타 내었다. $\mathrm{AlN}$ 의 첨가량에 따라 다소간의 차이가 있으나 $1400-1550^{\circ} \mathrm{C}$ 범위의 보다 낮은 온도에서 나타나는 큰 수 축속도는 $\mathrm{AlN}$ 과 $\mathrm{Al}_{2} \mathrm{O}_{3}$ 의 급격한 반응에 기인하는 것으 로, 두 번째의 큰 수축속도를 나타내는 $1650-1800^{\circ} \mathrm{C}$ 는 반응생성물인 $\mathrm{AlON}$ 기지상의 본격적인 치밀화가 개시되 는 온도로 생각된다.

$\mathrm{AlN}$ 의 첨가량이 감소할수록 반응소결의 향상과 상대적 으로 많은 양의 액상의 생성으로 인하여 수축의 정도는 증가하였으며, 따라서 높은 소결밀도를 나타내었다. 일례 로, $35.7 \mathrm{~mol} \% \mathrm{AlN}$ 이 첨가된 시편은 $1650^{\circ} \mathrm{C}$ 소결로 이

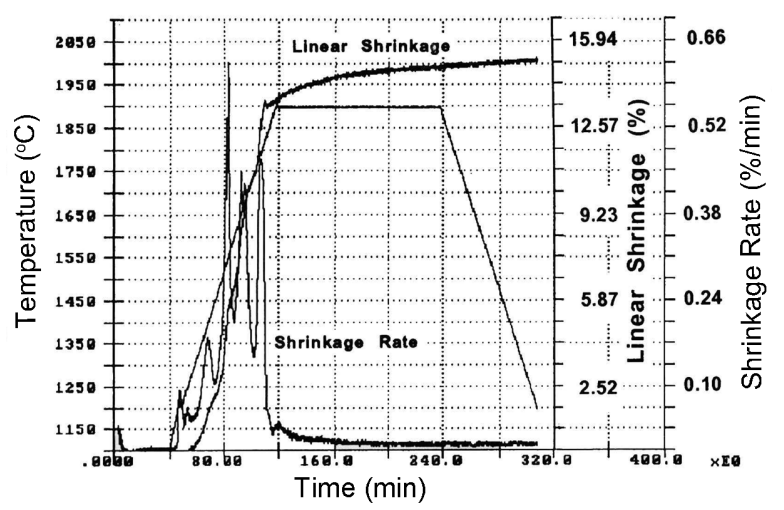

Fig. 1. Shrinkage and shrinkage rate curves of the $\mathrm{AlN}-\mathrm{Al}_{2} \mathrm{O}_{3}$ compact with $70 \mathrm{~mol} \%$ AlN content with sintering temperature at 1-atm nitrogen gas. 


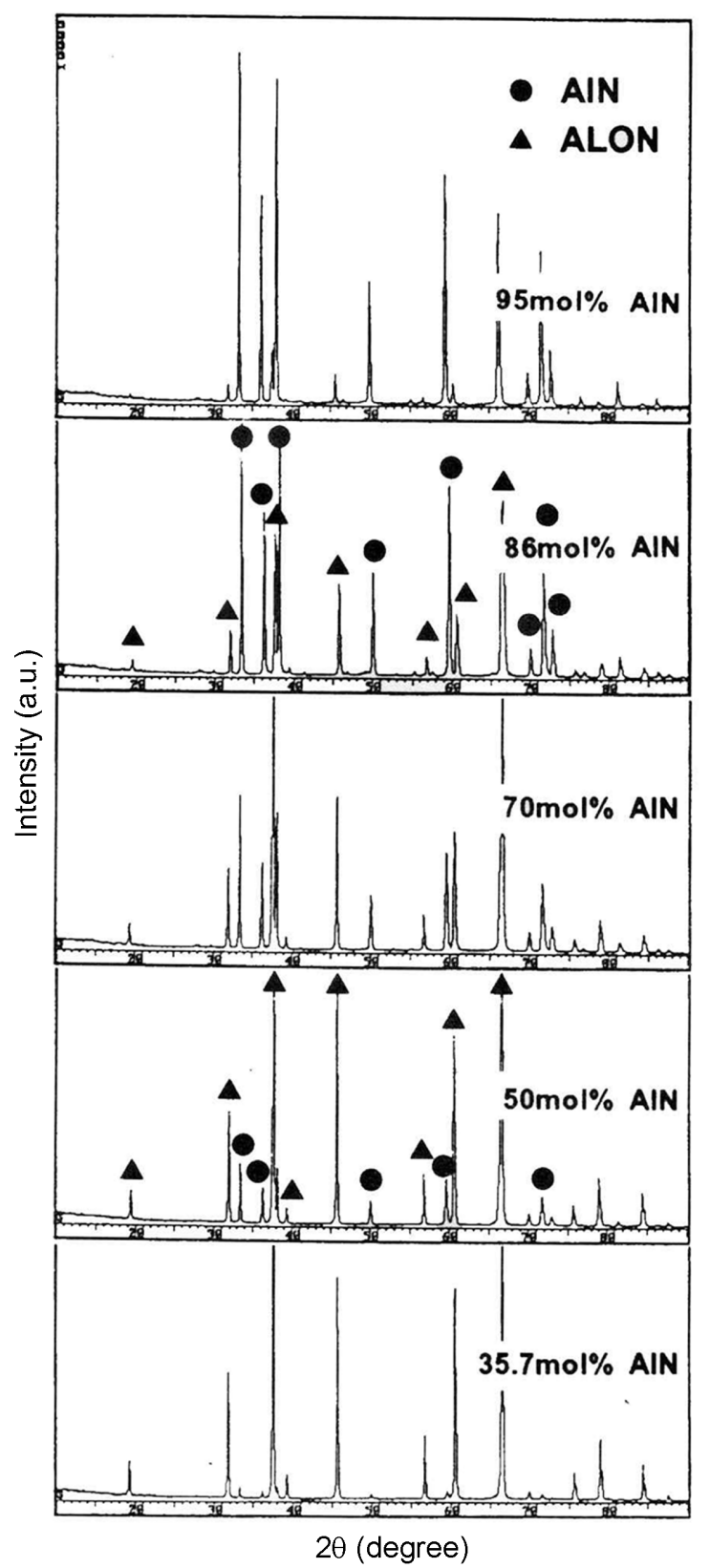

Fig. 2. X-ray diffraction patterns of the $\mathrm{AlN}-\mathrm{Al}_{2} \mathrm{O}_{3}$ compacts sintered at $1750^{\circ} \mathrm{C}$ for $2 \mathrm{~h}$ with various AIN contents.

미 이론밀도의 $95.2 \%, 1750^{\circ} \mathrm{C}$ 에서 $97.6 \%$ 인데 반하여 $70 \mathrm{~mol} \% \mathrm{AlN}$ 이 첨가된 시편의 경우는 동일한 소결온도 에서 각각 $91.9 \%, 96.2 \%$ 의 상대밀도를 나타내었다.

$1750^{\circ} \mathrm{C}$ 및 $1900^{\circ} \mathrm{C}$ 에서 소결한 $35.7,50,70,86,95 \mathrm{~mol} \%$ $\mathrm{AlN}$ 을 함유하는 $\mathrm{AlN}-\mathrm{Al}_{2} \mathrm{O}_{3}$ 물질의 $\mathrm{XRD}$ 회절패턴을 Figs. 2, 3에 각각 나타내었다. $35.7 \mathrm{~mol} \%$ 의 $\mathrm{AlN}$ 을 첨가 한 시편은 소결온도에 관계없이 $\mathrm{AlON}$ 과 약한 강도의 $\mathrm{AlN}$ 피크를 나타내었는데, 이는 Quinn 등 ${ }^{9}$ 이 30 및 $37.5 \mathrm{~mol} \%$ $\mathrm{AlN}$ 을 첨가하여 $1900^{\circ} \mathrm{C}$ 에서 48 시간 소결한 시편은 95 $98 \% \mathrm{AlON}$ 으로 구성된다는 결과와 유사하였다. 50 및

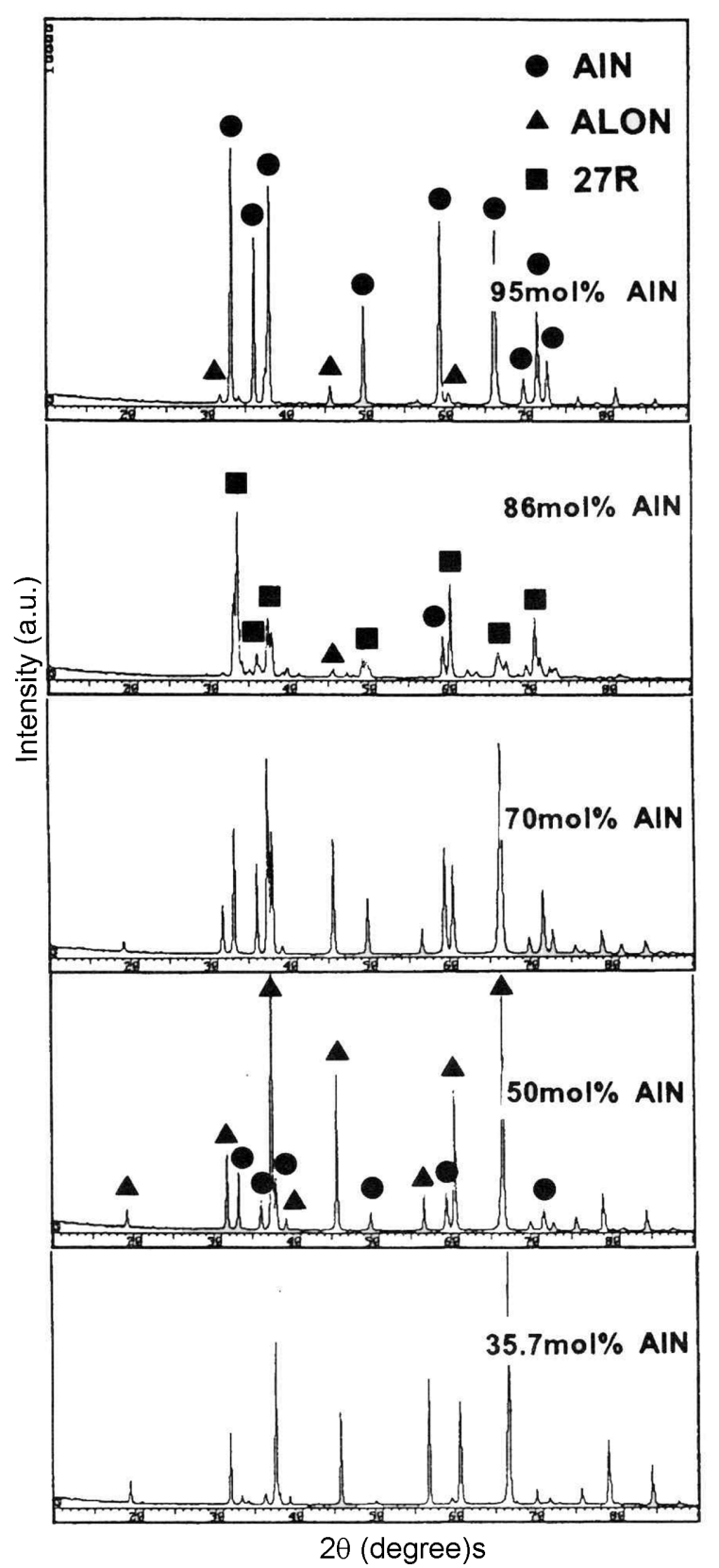

Fig. 3. X-ray diffraction patterns of the $\mathrm{AlN}-\mathrm{Al}_{2} \mathrm{O}_{3}$ compacts sintered at $1900^{\circ} \mathrm{C}$ for $2 \mathrm{~h}$ with various AIN contents.

$70 \mathrm{~mol} \% \mathrm{AlN}$ 을 첨가한 시편에서도 $\mathrm{AlON}$ 이 주상으로 존 재하였으며 $\mathrm{AlN}$ 함량이 높은 경우가 낮은 회절강도의 $\mathrm{AlON}$ 피크를 나타내었다. 이러한 결과는 $\mathrm{AlN}-\mathrm{Al}_{2} \mathrm{O}_{3}$ 계의 상태도에 관한 Gauckler와 Petzow ${ }^{16)}$ 및 McCauley와 $\operatorname{Corbin}^{17}$ 의 결과와도 일치한다. 특히 $86 \mathrm{~mol} \% \mathrm{AlN}$ 을 함 유하는 시편의 경우, $1900^{\circ} \mathrm{C}$ 에서 $27 \mathrm{R}$ 상으로 기지물질이 변화하였다. Lejus ${ }^{1}$ 가 $\mathrm{AlN}-\mathrm{Al}_{2} \mathrm{O}_{3}$ 계에서 $\mathrm{X}$ 상의 존재를 언 급한 후, Gauckler와 Petzow ${ }^{16)}$ 는 이 X상을 X6 및 X7이 혼합된 상이라고 하였다. 이 이외에도 1 기압 질소분위기 하에서 생성된 $12 \mathrm{H}, 21 \mathrm{R}, 27 \mathrm{R}$ 등의 여러 가지 다형의 존 


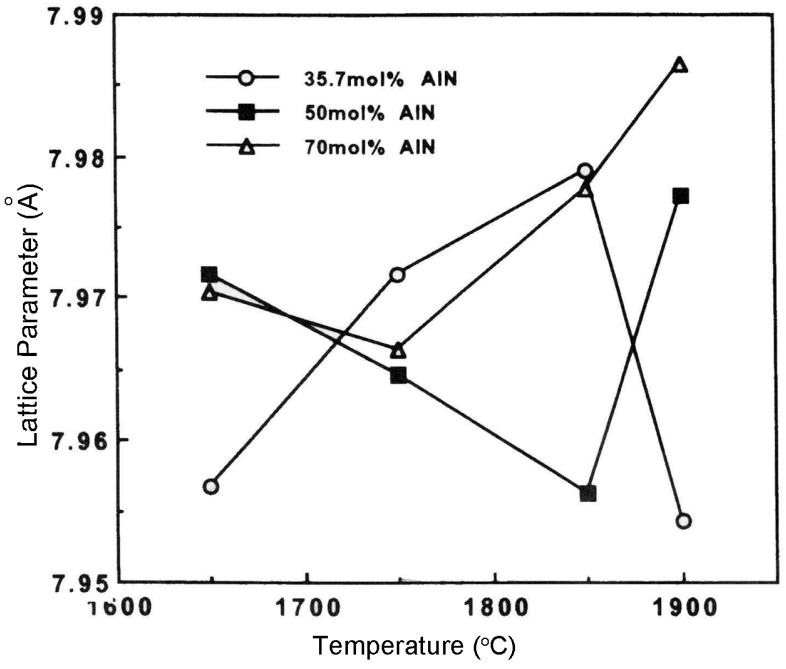

Fig. 4. AlON lattice parameter in the composites containing $35.7,50$, and $70 \mathrm{~mol} \% \mathrm{AIN}$ as a function of sintering temperature.

재가 알려져 있다. ${ }^{17)} 95 \mathrm{~mol} \% \mathrm{AlN}$ 이 첨가된 경우는 $\mathrm{AlN}$ 이 주상으로 동정되었으며, 소결온도가 증가할 때 회절강 도는 감소하였다.

알루미나에 $35.7,50,70 \mathrm{~mol} \% \mathrm{AlN}$ 을 각각 첨가한 소 결물질에 존재하는 $\mathrm{AlON}$ 의 격자상수를 소결온도의 함수 로 Fig. 4에 나타내었다. $35.7 \mathrm{~mol} \% \mathrm{AlN}$ 이 첨가된 시편 에서 $\mathrm{AlON}$ 의 격자상수는 소결온도의 증가와 더불어 증 가하여 $1850^{\circ} \mathrm{C}$ 에서 $7.979 \mathrm{~A}$ 의 최대치를 나타내었으나 $1900^{\circ} \mathrm{C}$ 에서는 $7.954 \mathrm{~A}$ 로 다시 감소하였다. $\mathrm{AlN}$ 이 $50 \mathrm{~mol} \%$ 첨가된 시편의 경우, $1650^{\circ} \mathrm{C}$ 에서의 격자상수는 $7.971 \mathrm{~A}$ 이었으며 소결온도의 증가와 더불어 그 값은 감소하여 $1850^{\circ} \mathrm{C}$ 에서 $7.956 \mathrm{~A}$ 를 나타내었다. 또한, $70 \mathrm{~mol} \% \mathrm{AlN}$ 첨가의 경우는 $\mathrm{AlON}$ 의 격자상수가 $1850^{\circ} \mathrm{C}$ 까지 거의 일 정한 $7.970 \mathrm{~A}$ 을 나타내었다. 공정조건의 상이로 인하여 단순 비교는 어렵지만, 알루미나에 30-37.5 mol\% AlN을 첨가한 $1925^{\circ} \mathrm{C}$ 소결시편에서 측정한 $\mathrm{AlON}$ 의 격자상수는 8.938-7.951 A ${ }^{17)} 20-30 \mathrm{~mol} \%$ AlN이 첨가된 $1700^{\circ} \mathrm{C}$ 소 결에서 7.934-7.948 $\mathrm{A}^{1)}$ 의 격자상수를 갖는 $\mathrm{AlON}$ 을 얻었 다는 연구결과가 있다.

$\mathrm{AlN}$ 을 $50,70,95 \mathrm{~mol} \%$ 첨가한 $\mathrm{AlN}_{-} \mathrm{Al}_{2} \mathrm{O}_{3}$ 압분체를 $1650-1900^{\circ} \mathrm{C}$ 에서 소결한 후 $\mathrm{AlN}$ 의 c축의 격자상수를 Fig. 5에 나타내었다. $95 \mathrm{~mol} \% \mathrm{AlN}$ 이 첨가된 시편에서 $\mathrm{AlN}$ 의 격자상수는 $1650^{\circ} \mathrm{C}$ 에서 $4.988 \mathrm{~A}, 1850^{\circ} \mathrm{C}$ 에서 $4.996 \mathrm{~A}, 1900^{\circ} \mathrm{C}$ 에서는 $4.992 \mathrm{~A}$ 이었다. 이들 값은 소결조제 로 $\mathrm{SiO}_{2}$ 를 사용한 경우의 $\mathrm{AlN}$ 의 격자상수 $4.976-4.978 \mathrm{~A}^{18)}$ 및 $\mathrm{CaO}$ 를 사용해서 얻은 $4.978-4.979 \mathrm{~A}^{19)}$ 보다는 다소 컸다. $\mathrm{AlN}$ 격자상수의 변화는 고용된 산소이온의 농도에 의존한다. Harris등 ${ }^{20}$ 은 어느 임계산소농도 (약 $0.75 \mathrm{at} \%$ ) 이하에서는 질소자리에 산소의 치환과 알루미늄 원자공

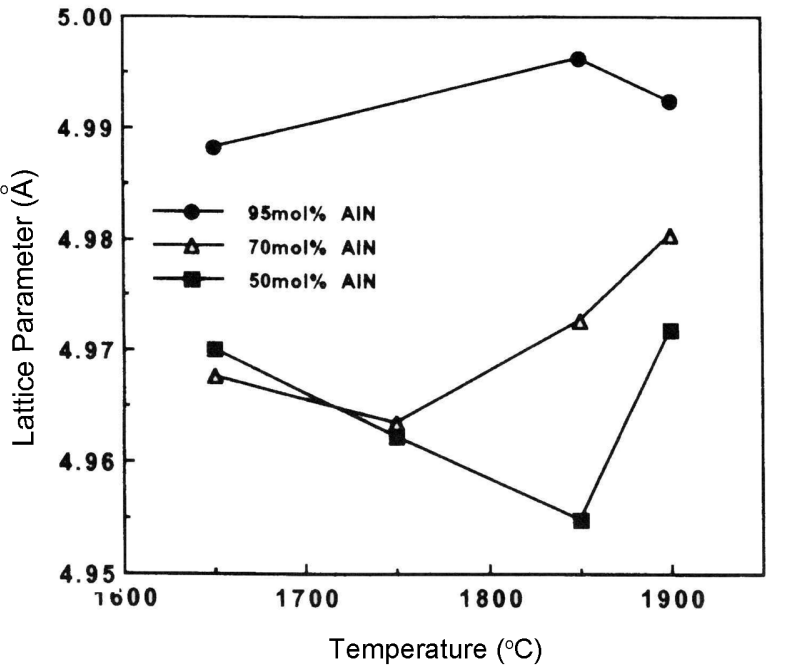

Fig. 5. AlN lattice parameter in the composites containing 50, 70 and $95 \mathrm{~mol} \% \mathrm{AlN}$ as a function of sintering temperature.

공의 생성 (즉, $O_{\mathrm{N}}+V_{\mathrm{Al}}$ )으로 인하여 $\mathrm{AlN}$ 단위격자의 수 축이 일어나며, 그 이상에서는 이러한 결함의 집합모델 (defect-cluster model)에 의해서 팽창이 일어난다고 제시하 였으나, 본 연구에서처럼 소결조제로서 소량의 $\mathrm{Y}_{2} \mathrm{O}_{3}$ 의 첨 가뿐만 아니라 출발물질로서 다량의 알루미나를 함유하 는 반응계에서 공정변수에 따른 생성 질화물의 격자정수 의 변화기구를 규명하기는 어렵다.

35.7 - $95 \mathrm{~mol} \% \mathrm{AlN}$ 을 첨가한 $\mathrm{AlN}_{-} \mathrm{Al}_{2} \mathrm{O}_{3}$ 물질을 1650 $1900^{\circ} \mathrm{C}$ 에서 2 시간 소결 후, 연마, 열에칭한 표면의 미세 구조를 관찰하였다. $50 \mathrm{~mol} \% \mathrm{AlN}$ 을 첨가한 $1650^{\circ} \mathrm{C}$ 소결 시편의 미세구조에서는 $35.7 \mathrm{~mol} \% \mathrm{AlN}$ 첨가의 경우와 마 찬가지로 $\mathrm{AlON}$ 뿐만 아니라 $\mathrm{AIN}$ 입자가 존재하였다 (Fig. 6). $1750^{\circ} \mathrm{C}$ 에서는 $\mathrm{AlON}$ 의 입계가 불분명하였으나 $1850^{\circ} \mathrm{C}$ 에서는 보다 명확해졌다. $1900^{\circ} \mathrm{C}$ 에서 보다 많은 액 상이 $\mathrm{AlON}$ 의 입계에 존재하였다. Fig. 7에서 볼 수 있는 바와 같이, $70 \mathrm{~mol} \% \mathrm{AlN}$ 을 첨가한 물질에서는 $1650^{\circ} \mathrm{C}$ 에 서 상당량의 $\mathrm{AlN}$ 입자의 존재와 불충분한 액상생성이 생 성되었으며, 아울러 $\mathrm{AlON}$ 의 치밀화가 거의 일어나지 않 았다. $1750^{\circ} \mathrm{C}$ 에서는 상당량의 액상이 생성되어 입계의 구 분이 불분명해졌으며, 소결온도가 $1850^{\circ} \mathrm{C}$ 이상으로 증가 하면서 이 액상은 대부분 $\mathrm{AlON}$ 의 입계에 존재하였다. $86 \mathrm{~mol} \% \mathrm{AlN}$ 을 첨가한 경우는(Fig. 8), $\mathrm{Y}_{2} \mathrm{O}_{3}$ 의 존재 하에 서 $\mathrm{AlN}$ 과 $\mathrm{Al}_{2} \mathrm{O}_{3}$ 가 $1650^{\circ} \mathrm{C}$ 에서 반응하여 이미 상당량의 액상을 생성함으로써 $\mathrm{AlN}$ 의 입계가 분명하지 않았으며, 일부 생성된 $\mathrm{AlON}$ 입자 관찰되었다. 소결온도가 $1750^{\circ} \mathrm{C}$ 로 증가하면서 $\mathrm{AlN}$ 입자의 성장이 뚜렷하였으나 그 입계 는 불분명했으며 $\mathrm{AlN}$ 의 입자 주위에 상당량의 액상이 생 성되었다. $1750^{\circ} \mathrm{C}$ 의 경우와는 매우 다른 미세구조가 $1850^{\circ} \mathrm{C}$ 에서 관찰되었다. 기공의 존재와 입자의 표면에 얇 


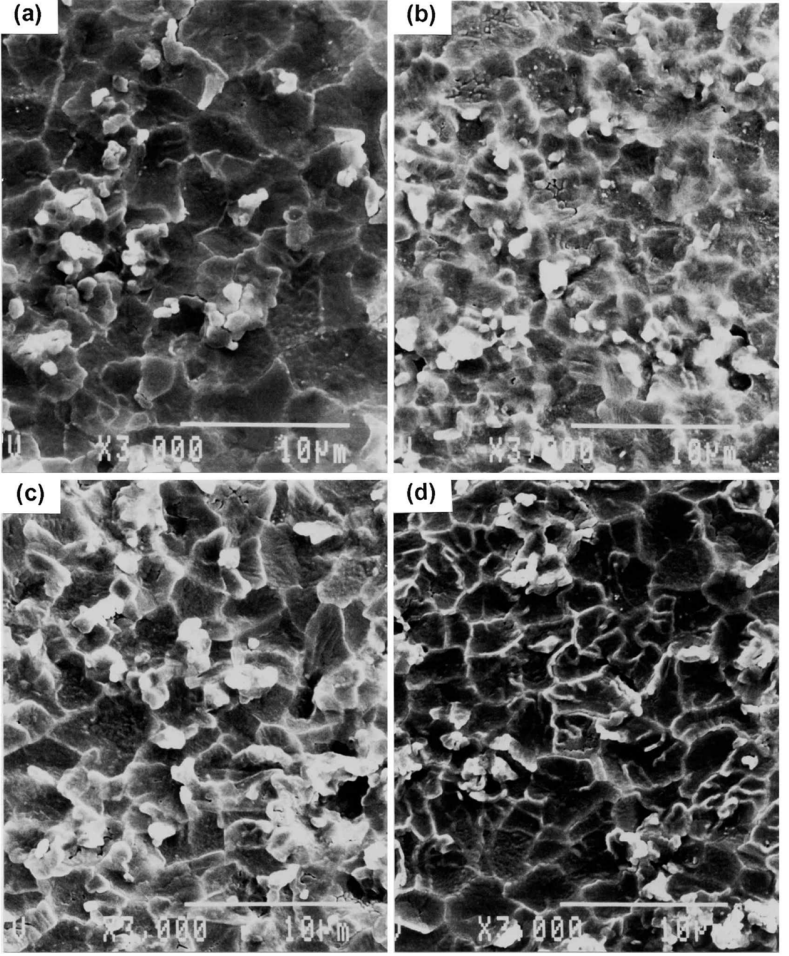

Fig. 6. SEM micrographs of polished and etched surface AIN$\mathrm{Al}_{2} \mathrm{O}_{3}$ specimens containing $50 \mathrm{~mol} \%$ AlN sintered at (a) 1650, (b) 1750 , (c) 1850 , and (d) $1900^{\circ} \mathrm{C}$ for $2 \mathrm{~h}$.

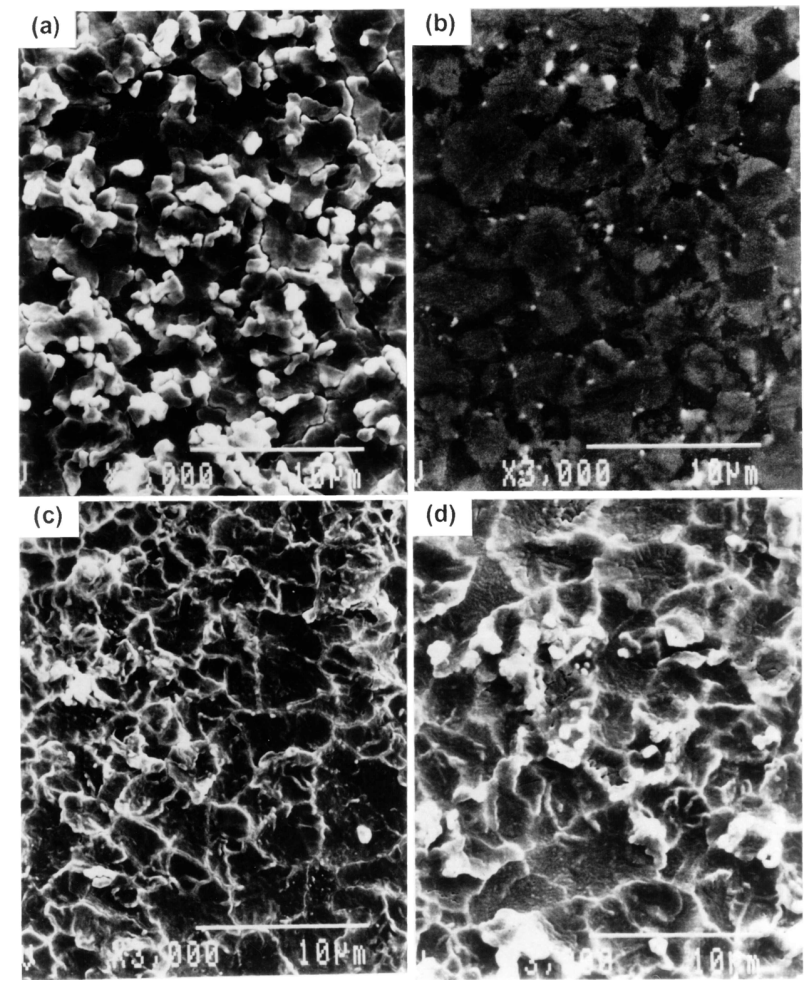

Fig. 7. SEM micrographs of polished and etched surface AIN$\mathrm{Al}_{2} \mathrm{O}_{3}$ specimens containing $70 \mathrm{~mol} \% \mathrm{AlN}$ sintered at (a) 1650 , (b) 1750 , (c) 1850 , and (d) $1900^{\circ} \mathrm{C}$ for $2 \mathrm{~h}$.
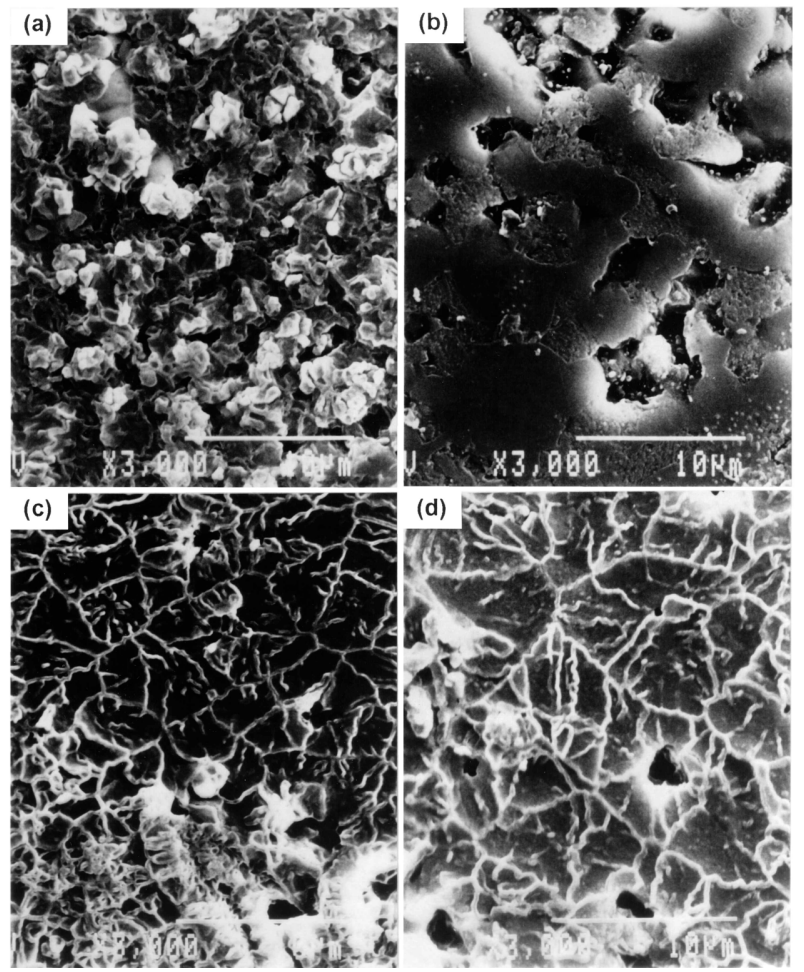

Fig. 8. SEM micrographs of polished and etched surface AIN$\mathrm{Al}_{2} \mathrm{O}_{3}$ specimens containing $86 \mathrm{~mol} \%$ AlN sintered at (a) 1650 , (b) 1750 , (c) 1850 , and (d) $1900^{\circ} \mathrm{C}$ for $2 \mathrm{~h}$.
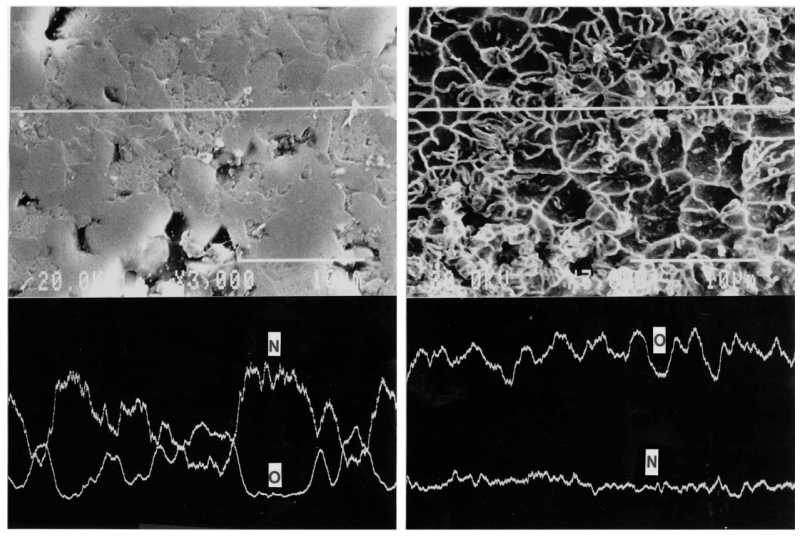

Fig. 9. EPMA analysis for $\mathrm{AlN}-\mathrm{Al}_{2} \mathrm{O}_{3}$ specimens containing $86 \mathrm{~mol} \%$ AlN sintered at $1750^{\circ} \mathrm{C}$ (left) and $1850^{\circ} \mathrm{C}$ (right) for $2 \mathrm{~h}$.

은 액상의 띠가 상당히 형성되었다. 이러한 미세구조의 차이는 $1750^{\circ} \mathrm{C}$ 에서의 주상이 $\mathrm{AlN}$ 인데 반하여 소결온도 가 $1850^{\circ} \mathrm{C}$ 로 증가하면서 주상이 그것의 다형인 $27 \mathrm{R}$ 으로 변하기 때문으로 생각된다. 이 두 온도에서의 주된 구성 상의 상이에 따른 미세구조의 차이를 확인하기 위하여 EPMA를 이용하여 line profile에 의한 성분분석을 행하고, 그 결과를 Fig. 9에 나타내었다. $1750^{\circ} \mathrm{C}$ 에서 소결한 시편 에서는 $\mathrm{AlN}$ 과 액상의 구분이 명확하였으나 $1850^{\circ} \mathrm{C}$ 소결 


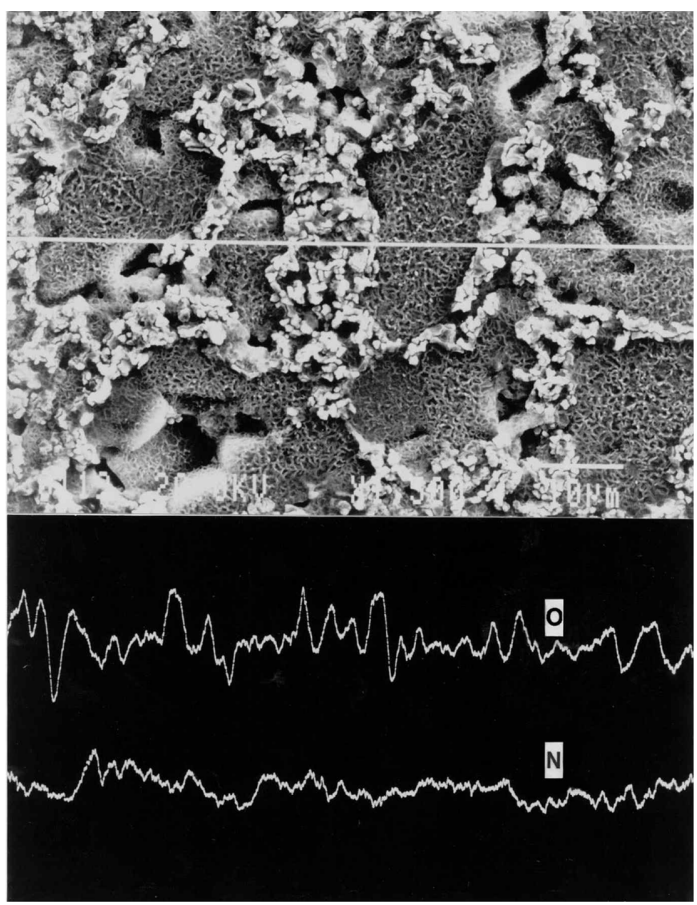

Fig. 10. EPMA analysis for $\mathrm{AIN}-\mathrm{Al}_{2} \mathrm{O}_{3}$ specimen containing $95 \mathrm{~mol} \%$ AlN sintered at $1850^{\circ} \mathrm{C}$ for $2 \mathrm{~h}$.
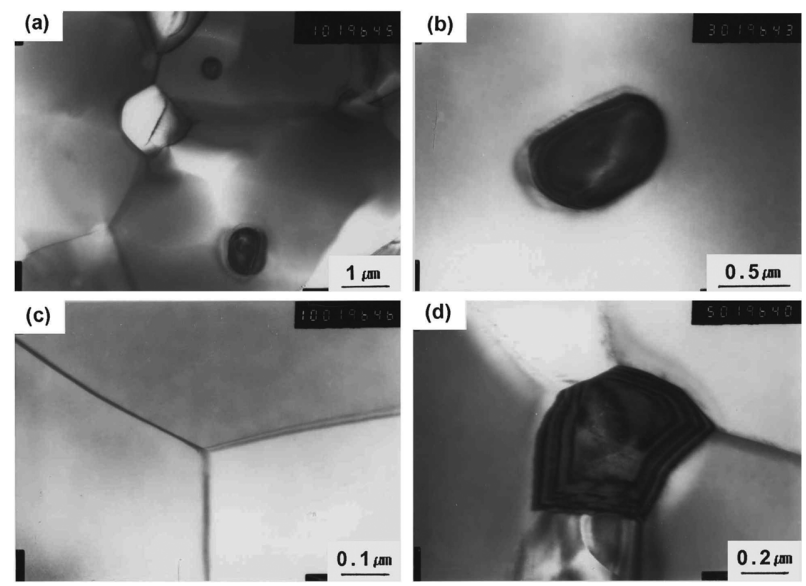

Fig. 11. STEM photographs of $\mathrm{AIN}-\mathrm{Al}_{2} \mathrm{O}_{3}$ specimens containing $50 \mathrm{~mol} \% \mathrm{AIN}$ sintered at $1750^{\circ} \mathrm{C}$ for $2 \mathrm{~h}$.

의 경우는 산소가 상당히 고용되어 있음을 알 수 있다. 아울러, $1850^{\circ} \mathrm{C}$ 에서 소결한 $95 \mathrm{~mol} \% \mathrm{AlN}$ 을 첨가한 물질 의 미세구조와 EPMA 분석결과를 Fig. 10 에 나타내었다. $\mathrm{XRD}$ 분석결과 $\mathrm{AlON}$ 으로 확인된 secondary phase가 기지 물질로부터 분리되어 존재하였다. AlN 입자의 표면에 존 재하는 일부의 액상으로 인하여 산소성분이 검출되었으 며 SEM 사진의 이차상의 입자에서 산소와 질소성분이 공존하였다.

$1750^{\circ} \mathrm{C}$ 에서 소결한 시편의 미세구조를 주사투과전자현 미경 (STEM)을 이용하여 좀 더 세밀히 관찰하였다(Fig. 11).

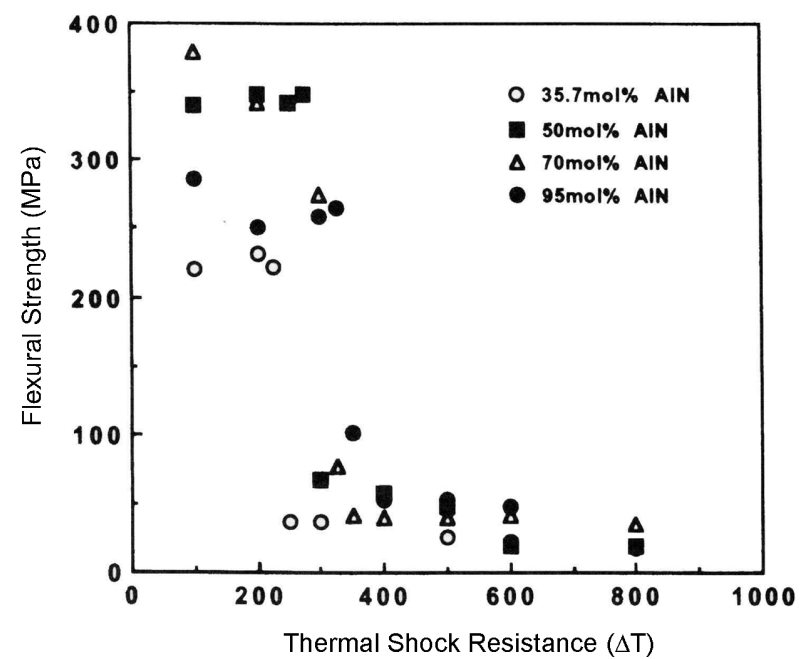

Fig. 12. Bend strength of $\mathrm{AlN}-\mathrm{Al}_{2} \mathrm{O}_{3}$ specimens with various AlN contents as a function of quenching temperature.

0.4-1 $1 \mu \mathrm{m}$ 정도의 미세한 게재물이 널리 분포되어 있었다. $\mathrm{AlN}$ 입계가 명확히 구분되었으며 입계와 삼중점 하에서 유리상이 거의 존재하지 않았다. $\mathrm{AlN}$ 의 입계에서 특이한 모양의 $\mathrm{AlON}$ 입자가 확인되었다.

Fig. 12에 $\mathrm{AlN}$ 의 첨가량이 다른 4가지 입자복합체의 열 충격저항성을 나타내었다. $35.7 \mathrm{~mol} \% \mathrm{AlN}$ 을 첨가한 경우 는 $1700^{\circ} \mathrm{C}, 2$ 시간, 50 및 $70 \mathrm{~mol} \% \mathrm{AlN}$ 을 첨가한 경우는 $1800^{\circ} \mathrm{C}, 2$ 시간, $95 \mathrm{~mol} \% \mathrm{AlN}$ 을 첨가한 경우는 $1850^{\circ} \mathrm{C}$ 에 서 2 시간동안 1 기압의 질소분위기에서 소결한 시편을 열 충격저항의 측정에 사용하였다. 주로 $\mathrm{AlON}$ 결정상으로 구성된 $35.7 \mathrm{~mol} \% \mathrm{AlN}$ 을 첨가한 물질의 임계온도차 $\left(\Delta \mathrm{T}_{\mathrm{c}}\right.$, critical temperature difference)는 약 $215^{\circ} \mathrm{C}$ 로, 이 값은 Quinn 등 ${ }^{9}$ 이 반응소결하여 제조한 $\mathrm{AlON}$ 의 $175-180^{\circ} \mathrm{C}$, 그리고 알루미나에 $73 \mathrm{~mol} \% \mathrm{AlN}$ 을 첨가하여 가압소결한 투광성 $\mathrm{AlON}^{4)}$ 의 임계온도차, $200^{\circ} \mathrm{C}$ 보다는 조금 높은 값을 나타 내었다. 열충격에 의해서 현저한 강도감소를 나타내는 임 계온도차는 $35.7 \mathrm{~mol} \% \mathrm{AlN}$ 의 첨가 (주로 $\mathrm{AlON}$ 으로 구성) 에 비하여 $50\left(300^{\circ} \mathrm{C}\right)$ 및 $70 \mathrm{~mol} \%\left(275^{\circ} \mathrm{C}\right) \mathrm{AlN}$ 이 첨가 된 시편 $(\mathrm{AlON}$ 기지에 $\mathrm{AlN}$ 이 분산되어 있는 형태의 입 자복합체)에서 다소 높은 값을 나타내었다. 이러한 차이 는 $\mathrm{AlN}$ 의 임계온도차가 $\mathrm{AlON}$ 의 그것보다 높은 데 기인한 다. $95 \mathrm{~mol} \% \mathrm{AlN}$ 을 첨가한 경우의 임계온도차는 $300^{\circ} \mathrm{C}$ 정도로, 소결조제로 $\mathrm{Y}_{2} \mathrm{O}_{3}$ 와 $\mathrm{SiO}_{2}$ 를 사용하여 hot-pressing 하여 제조한 $\mathrm{AlN}$ 소결체의 임계온도차, $250^{\circ} \mathrm{C}^{21)}$ 보다 약 간 높았다.

\section{4. 결 론}

최소한 2 개의 결정상과 대부분의 배치조성에서 입계에 유리상을 함유하는 입자복합체가 35.7-95 mol\% $\mathrm{AlN}$ 과 
소량의 $\mathrm{Y}_{2} \mathrm{O}_{3}$ 을 함유하는 $\mathrm{AlN}_{-} \mathrm{Al}_{2} \mathrm{O}_{3}$ 계에서 $1900^{\circ} \mathrm{C}$ 이하 의 제어된 분위기소결에서 얻어졌다. 조성에 관계없이 유 사한 소결패턴을 나타내었다. $\mathrm{AlN}$ 첨가량의 증가와 더불 어 동일한 온도에서의 수축의 정도는 감소하였으며 $\mathrm{AIN}$ 과 $\mathrm{Al}_{2} \mathrm{O}_{3}$ 사이의 반응개시온도와 반응생성물, $\mathrm{AlON}$ 의 본 격적인 치밀화가 시작하는 온도부근에서 큰 수축속도를 나타내었다. $70 \mathrm{~mol} \%$ 이하의 $\mathrm{AlN}$ 을 첨가하여 제조한 소 결체의 미세구조는 $\mathrm{AlN}$ 입자가 분산된 다결정의 $\mathrm{AlON}$ 기지로 구성되어 있었다. 반면에, $86,95 \mathrm{~mol} \% \mathrm{AlN}$ 함유 하는 물질은 $\mathrm{AlON}$ 또는 27R 다형입자가 분산된 $\mathrm{AlN}$ 기 지로 구성되어 있었다. 열충격저항성은 $\mathrm{AlON}$ 에 비하여 $\mathrm{AlN}$ 결정상을 상대적으로 많이 함유하고 있는, 즉 알루 미나의 첨가량이 적은 물질에서 우수하였다.

\section{Acknowledgment}

이 논문은 부산대학교 자유과제 학술연구비(2년)에 의 하여 연구되었음.

\section{REFERENCES}

1. A. Lejus, "Formation at High Temperature of Nonstoichiometric Spinels and of Derived Phases in Several Oxide Systems Based on Alumina and in the System AluminaAluminum Nitride," Rev. Int. Hautes Temp. Refract., 1 5395 (1964).

2. J. W. McCauley, "A Simple Model for Aluminum Oxynitride Spinel," J. Am. Ceram. Soc., 61 [7-8] 372-73 (1978).

3. H. Takebe, T. Kameda, M. Komatsu, K. Komeya, and K. Morinaga, "Fabrication of Translucent Sintered Aluminum Oxynitride Spinel (ALON)," J. Ceram. Sco. Jpn. Inter. Edn., 97 [1122] 163-69 (1989).

4. G. Yamaguchi, "On the Refractive Power of the Lower Valent Al Ion $\left(\mathrm{Al}^{+}\right.$or $\left.\mathrm{Al}^{++}\right)$in the Crystal," Bull. Chem. Soc. Jpn., 23 [3] 89-90 (1950).

5. H. X. Willems, M. M. R. M. Hendrix, G. de With, and R. Metselaar, "Thermodynamics of Alon II: Phase Relations," J. Eur. Ceram. Soc., 10 [4] 339-46 (1992).

6. J. W. McCauley and N. D. Corbin, "Phase Relations and Reaction Sintering of Transparent Cubic Aluminum Oxynitride (AlON)," J. Am. Ceram. Soc., 62 [9-10] 459-76 (1979).

7. N. D. Corbin, "Aluminum Oxynitride Spinel: A Review," $J$. Eur. Ceram. Soc., 5 [3] 143-54 (1989).

8. T. M. Hartnett, E. A. Maguire, R. L. Gentilman, N. D. Corbin, and J. W. McCauley, "Aluminum Oxynitride Spinel
(ALON): A New Optical and Multimode Window Material," Ceram. Eng. Sci. Proc., 3 67-76 (1982).

9. G. D. Quinn, N. D. Corbin, and J. W. McCauley, "Thermomechanical Properties of Aluminum Oxynitride Spinel," Am. Ceram. Soc. Bull., 63 723-30 (1984).

10. N. D. Corbin, The Influence of Carbon, Nitrogen and Argon on Aluminum Oxynitride Spinel Formation; pp. 113-16, in M. S. Thesis, Massachusetts Institute of Technology, Cambridge, 1982.

11. E. A. Maguire, T. M. Harnet, and R. L. Gentilman, "Method of Producing Aluminum Oxynitride Having Improved Optical Characteristics," U. S. Patent No. 4686070, 11 August 1987.

12. I. U. Kim and V. L. Richards, "High-temperature Electrical Conductivity of Aluminum Oxynitride Spinel," J. Am. Ceram. Soc., 68 C-120 (1985).

13. Y. W. Kim, B. H. Park, H. C. Park, Y. B. Lee, K. D. Oh, and F. L. Riley, "Sintering, Microstructure, and Mechanical Properties of AlON-AlN Particulate Composites," Brit. Ceram. Trans., 97 [3] 97-104 (1997).

14. Y. W. Kim, H. C. Park, Y. B. Lee, K. D. Oh, and R. Stevens, "Reaction Sintering and Microstructural Development in the System $\mathrm{Al}_{2} \mathrm{O}_{3}$-AIN," J. Eur. Ceram. Soc., 21 [13] 2383-91 (2001).

15. Y. W. Kim, Y. W. Oh, S. Y. Yoon, R. Stevens, and H. C. Park, "Thermal Diffusivity of Reaction-Sintered AlON/ $\mathrm{Al}_{2} \mathrm{O}_{3}$ Particulate Composites," Ceram. Inter, 34 [8] 184955 (2008).

16. L. J. Gauckler and G. Petzow, "Representation of Multicomponent Silicon Nitride Based Systems," pp. 41-60 in Nitrogen Ceramics, Ed. by F. L. Riley, Noordhoff Publishing Co., Leyden, 1977.

17. J. W. McCauley and N. D. Corbin, "High Temperature Reactions and Microstructures in the $\mathrm{Al}_{2} \mathrm{O}_{3}$-AIN System," pp. 111-18 in Progress in Nitrogen Ceramics, Ed. by F. L. Riley, Martinus Nijhoff, Boston, 1983.

18. P. S. de Baranda, A. K. Knudsen, and E. Ruh, "Effect of $\mathrm{CaO}$ on the Thermal Conductivity of Aluminum Nitride," $J$. Am. Ceram. Soc., 76 [7] 1751-60 (1993).

19. P. S. de Baranda, A. K. Knudsen, and E. Ruh, "Effect of Silica on the Thermal Conductivity of Aluminum Nitride," $J$. Am. Ceram. Soc., 76 1761-71 (1993).

20. J. H. Harris, R. A. Youngman, and R. G. Teller, "On the Nature of the Oxygen-related Defect in Aluminum Nitride," J. Mater. Res., 5 1763-73 (1990).

21. K. Komeya and F. Noda, "Aluminum Nitride and Silicon Nitride for High Temperature Vehicular Gas Turbine Engines," Toshiba Review, 92 13-8 (1974). 